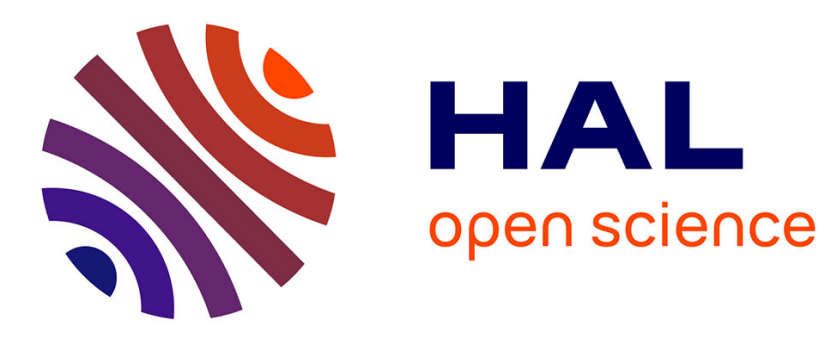

\title{
NeuroQ: A neurophobia screening tool assesses how roleplay challenges neurophobia
}

\author{
Eavan Mcgovern, Céline Louapre, Julien Cassereau, Constance
}

Flamand-Roze, Elise Corsetti, Prasanthi Jegatheesan, David Bendetowicz, Camille Giron, Margaux Dunoyer, Nicolas Villain, et al.

\section{To cite this version:}

Eavan Mcgovern, Céline Louapre, Julien Cassereau, Constance Flamand-Roze, Elise Corsetti, et al.. NeuroQ: A neurophobia screening tool assesses how roleplay challenges neurophobia. Journal of the Neurological Sciences, 2021, 421, pp.117320. 10.1016/j.jns.2021.117320 . hal-03156553

\section{HAL Id: hal-03156553 https://hal.science/hal-03156553}

Submitted on 8 Mar 2021

HAL is a multi-disciplinary open access archive for the deposit and dissemination of scientific research documents, whether they are published or not. The documents may come from teaching and research institutions in France or abroad, or from public or private research centers.
L'archive ouverte pluridisciplinaire HAL, est destinée au dépôt et à la diffusion de documents scientifiques de niveau recherche, publiés ou non, émanant des établissements d'enseignement et de recherche français ou étrangers, des laboratoires publics ou privés. 


\section{NeuroQ: A neurophobia screening tool assesses how roleplay challenges neurophobia}

Eavan McGovern, MD, $\mathrm{PhD}^{1,2,3^{*}}$, Céline Louapre, MD, $\mathrm{PhD}^{1,2,3^{*}}$, Julien Cassereau, MD, $\mathrm{PhD}^{4,5^{*}}$, Constance Flamand-Roze, $\mathrm{PhD}^{6}$, Elise Corsetti, $\mathrm{PhD}^{1}$, Prasanthi Jegatheesan, $\mathrm{PhD}^{1}$, David Bendetowicz, $\mathrm{MD}^{1,2,3}$, Camille Giron, $\mathrm{MD}^{1,2}$, Margaux Dunoyer, $\mathrm{MSc}^{1,2}$, Nicolas Villain, MD, $\mathrm{PhD}^{1,2,3}$, Marie-Christine Renaud, $\mathrm{MD}^{2}$, Paul Sauleau, MD, $\mathrm{PhD}^{7,8}$, Laure Michel, MD, $\mathrm{PhD}^{7,9}$, Marc Vérin, MD, PhD ${ }^{7,8,9}$, Yulia Worbe', MD, PhD ${ }^{2,3,10}$, Bruno Falissard, MD, $\mathrm{PhD}^{11,12}$, Emmanuel Roze, MD, $\mathrm{PhD}^{1,2,3}$

1. AP-HP, Hôpital Pitié-Salpêtrière, Département de Neurologie, Paris, France

2. Sorbonne Université

3. INSERM U1127, CNRS 7225, Institut du Cerveau, Paris, France

4. Université d'Angers, Faculté de Médecine, Angers, France

5. Hôpital Universitaire d'Angers, Angers, France

6. Centre Hospitalier Sud-Francilien, Département de Neurologie, Corbeil, France

7. Hôpital Universitaire de Rennes, Département de Neurologie, Rennes, France

8. Institut des Neurosciences Cliniques de Rennes, équipe EA4712, Rennes, France

9. Université Rennes 1, Rennes, France

10. AP-HP, Hôpital Saint Antoine, Service de Neurophysiologie, Paris, France

11. Centre de Recherche en Epidémiologie et Santé des Populations, Villejuif, France

12. Université Paris-Saclay, Faculté de Médecine, Département de Santé Publique, Villejuif, France

${ }^{*}$ Authors contributed equally to the manuscript

\section{Manuscript statistics}

Title character count: 72

Abstract word count: 230

Text word count: 3178

Tables: 3

Figures: 2

Citations: 38

Key words: neurophobia, active learning, simulation, medical school, education

Running Title: NeuroQ: neurophobia and roleplay 
Study funding: no funding

Declaration of interest: none.

Corresponding author: Eavan McGovern. eavanmcgovern@rcsi.com. 0871905003

Data availability statement: The data that support the findings of this study are available from the corresponding author upon reasonable request

\section{ABSTRACT}

Background: Neurophobia is a chronic disease of medical students and junior doctors. Early detection is needed to facilitate prevention and management as this fear can negatively impact patient care.

Methods: We conducted a two-part mono-centric study at the faculty of Medicine, Sorbonne University, in Paris. Part one: a cross-sectional study to validate a newly constructed neurophobia scale, NeuroQ. Part two: a prospective longitudinal study to assess the impact of The Move on student neurophobia using NeuroQ. A populationbased sample of second-year medical students of the 2019 and 2020 class of the Faculty of Medicine of Sorbonne University were invited to participate.

Results: NeuroQ incorporates the main themes of the neurophobia definition and demonstrates uni-dimensionality. Three hundred and ninety-five medical students participated in the study (mean age was 20.0 years, SD: 2.1 years) assessing the effect of The Move teaching on neurophobia. Two hundred and eighty-eight (72.9\%) students were female. After the Move teaching the mean NeuroQ score was significantly lower compared to the baseline NeuroQ score (mean [SD] variation, $-1.1[2.6], p<0.001$ ).

There was a $22.3 \%$ relative reduction in the number of neurophobic students after The Move teaching. 
Conclusion: Our results highlight the utility of NeuroQ in assessing (i) baseline neurophobia and (ii) the impact of pre-clinical educational interventions on neurophobia. Furthermore, we have shown the importance of pre-clinical educational interventions, such as The Move, in tackling neurophobia.

\subsection{INTRODUCTION}

Neurology is considered a difficult medical discipline by medical students and junior doctors ${ }^{1-6}$. Neurophobia is a fear of neural science and clinical neurology, mostly due to an inability to apply knowledge of neural science to clinical situations ${ }^{7}$. Neurophobia is a global phenomenon ${ }^{3,5,8-14}$, and was originally cited as affecting $50 \%$ of medical students ${ }^{7}$. Recent literature suggests it affects approximately $30 \%$ of medical students ${ }^{3,9,15,16}$, one-third of junior doctors and general practitioners ${ }^{3,10,12}$.

Neurophobia begins in pre-clinical years when medical students are first exposed to academic neuroscience and increases over the course of medical school ${ }^{16-18}$. Interventions for phobias are most effective when started early. Pre-clinical years in medical school represent a therapeutic window for neurophobia. A scale which can detect neurophobia at onset, is needed. Several scales exist in the literature. However, most rely on students with prior exposure to neurology patients ${ }^{3,9,12,13}$. Similarly, proposed alternate teaching models usually target medical students during the neurology clinical clerkship ${ }^{11,12,15,18-24}$. Furthermore, many existing scales have not 
been properly validated and some include questions not directly related to neurophobia 16.

The Move is a pre-clinical simulation teaching method developed at the Sorbonne University in Paris. It uses an intuitive learning style to understand how neurological disease manifests clinically ${ }^{25,26}$.

The aim of our project was two-fold. Firstly, we sought to validate a neurophobia scale suitable for pre-clinical medical students. Secondly, using this scale, we aimed to see if the Move teaching approach could reduce neurophobia amongst undergraduate medical students.

\subsection{METHODS}

\subsubsection{Study design and setting}

General design of the study is presented in Figure 1.

We conducted a mono-centric study at the Faculty of Medicine of Sorbonne University over a two-year period and comprising 2 steps: i) a cross-sectional study to validate a neurophobia scale (in 2019); ii) a prospective longitudinal study to assess the effect of The Move program in undergraduate medical students using the neurophobia scale validated in the first step (in 2020).

\subsubsection{Standard protocol approval and registration.}


All students participating in the study received written information on the objectives of the study to meet full regulatory compliance. Data collection was anonymized using inclusion number randomly assigned. Second-year medical students (of the 2019 and 2020 class) at the Faculty of Medicine of Sorbonne University who had completed their neuroscience teaching block and The Move semiology teaching program were eligible to participate in the study. This study received approval from the Inserm ethics committee (CEEI-IRB).

\subsubsection{Scale construction}

Following review of the existing literature, a scale was constructed to incorporate core elements of the neurophobia definition: perceived difficulty, complexity of the subject matter and student lack of confidence for neurology. We were careful not to include any questions pertaining to the clinical encounter, as this item is unsuitable for medical students in pre-clinical years. Preliminary longer versions of the scale were refined to avoid repetition of the themes and to optimize the time taken to fill out the questionnaire, A preliminary version of the scale was circulated between authors to reach a consensus agreement. An initial version of the scale (NeuroQ-i) was finalised and comprised of six items.

Students were instructed to respond to each statement on NeuroQ-I using a five-item Likert scale (strongly disagree to strongly agree). To limit acquiescence response bias, the statements were balanced between sentences reflecting high or low neurophobia. 
Statements reflecting low neurophobia were reversed-scored. The maximum score was 30: higher scores correspond to a greater neurophobia.

A second questionnaire by Schon et al (Schon questionnaire), was used for the purposes of convergent validation ${ }^{1}$. This questionnaire has previously been used to assess neurophobia amongst medical students and junior doctors ${ }^{1}$. It comprises four items and assesses the following themes: interest, knowledge, difficulty, confidence at assessing a neurology patient. The last two questions, which measure difficulty and confidence at assessing a neurology patient are scored from 1 to 5 and form a composite score for neurophobia. Lower scores indicate greater difficulty and low confidence. A total score of 4 or below for these 2 items indicates a neurophobic individual ${ }^{1}$.

\subsubsection{Scale validation}

NeuroQ was validated on the basis of (1) the internal validity of the instrument (item analysis, reliability and factor structure) (2) convergent validity (comparison with Schon questionnaire).Therefore, we invited one class of second-year medical students after completing their neuroscience teaching block to fill NeuroQ-i (for internal validity) and Schon questionnaire (for convergent validity).

\subsubsection{The Move teaching intervention}

Second-year medical students of the Faculty of Medicine of Sorbonne University received The Move teaching as part of their regular curriculum after the neuroscience teaching block. Students were divided into groups of 30-35 students. They received five 
three-hours teaching sessions (one per week) led by two to three neurologists acting as The Move coaches. During the sessions, student volunteers were taught neurology semiology (how neurological disease clinically manifests) and trained to roleplay a patient with various neurological syndromes. Other students roleplayed the physician examining the patient. The importance of not mocking students or patients was emphasized. Students not comfortable with roleplay were given the option to be observers. During the final 2 hour session, students from each group performed preprepared sketches of clinical scenarios of the various neurological syndromes in front of their peers and a jury (panel of experts). See video in supplementary files. The students gave their written informed consent for the purposes of videotaping and publication of this video.

\subsubsection{The Move effect on neurophobia}

Second-year medical students of the next academic year were asked to complete the final validated version of the scale (NeuroQ) at the start of the 1st teaching session of The Move program (baseline), and at the end of the 5th teaching session (follow-up). Additionally, baseline demographic data was collected and included: age, sex, presence of: i) a physician; ii) a neurologist; iii) a person with neurological disease in the family circle, and the interest in a career in neurology.

\subsubsection{Statistical analysis}

\subsubsection{Scale validation}




\section{i) Internal validation}

Firstly, we calculated the rate of non-response for individual scale items. The floor and ceiling effect of individual scale items was calculated with visual observation of histograms depicting individual responses. Pearson's correlation coefficient was used to examine item redundancy and the scree plot to assess scale uni-dimensionality. Finally, Cronbach's alpha was used to explore the internal consistency of scale items.

\section{ii) Convergent validation}

Using Pearson's correlation coefficient, Neuro-Qi was correlated with the Schon questionnaire. Listwise deletion was used for incomplete or missing data.

\subsubsection{Determination of a cut-off score}

We used purposive sampling to divide 100 students' responses into three groups based on their neurophobic score: weak, medium and high score. Three examiners (two neurologists, one speech and language therapist), blinded to the sampling methodology, determined if the student was neurophobic or not based on individual responses. ROC curves were generated for each examiner and the score with the best sensibility and sensitivity were retained for each examiner.

\subsubsection{The Move effect on neurophobia}


Descriptive statistics were performed on demographic parameters and the NeuroQ score (global and for each question). The statistical significance of the modification of the NeuroQ score at follow-up compared to baseline was performed using a paired ttest. Signed rank Wilcoxon test was used to compare NeuroQ items at follow-up versus baseline. The difference in the proportion of students with neurophobia at follow-up versus baseline was tested with a Fisher test. The associations between i) the initial NeuroQ score; ii) the NeuroQ score change, and the demographic characteristics were assessed using linear regression model for numerical variables, t-test or ANOVA for categorical variables. Non-parametric tests were used for testing the association between NeuroQ items and demographic characteristics. Two-sided $p<.05$ was considered statistically significant. Data analyses were performed in Python using Pandas package version 1.0.3, Scipy v1.4.1 and Statsmodels v0.11.1. Listwise deletion was used for incomplete or missing data.

\section{Data availability statement}

All data is available at the Department of Neurology of the Salpêtrière Hospital (Paris, France).

\subsection{RESULTS}

\subsubsection{Internal validation of NeuroQ}

During the academic year 2019, 352 students completed NeuroQ-i comprising 6 items. An item-by-item analysis of the entire sample was carried out and showed no floor or ceiling effect. Parallel analysis using the scree plot demonstrated one main theme, suggesting uni-dimensionality of Neuro-Qi. 
Pearson' correlation coefficient between item's score showed a satisfactory correlation between all items, except item 2, which correlates little with the other ones.

The internal consistency evaluated by Cronbach's alpha coefficient for 6 items was 0.55 , which is relatively low - but expected - due to the low total number of items. By removing item 2 , this coefficient increased to 0.58 . This indicates that this item does not assess the same dimension and must be removed from the initial questionnaire. We therefore obtained a 5 -item scale. Each item being listed from 1 to 5 , the minimum value is 5 and the maximum value is 25 . The validated version of NeuroQ is presented in Table 1.

\subsubsection{Convergent validation of NeuroQ}

Among 352 students completing both NeuroQ-i and the Schon questionnaire, we obtained incomplete or missing data in the Schon questionnaire $(n=26)$, mainly because this questionnaire is not entirely suitable for students who have not been in contact with neurological patients. Therefore, a total of 326 student responses were included in the convergent validation analysis. We found a positive correlation between the two scales with a Pearson coefficient of $0.173(p=0.003)$.

\subsubsection{Cut-off of NeuroQ}

Using ROC curves to assess the sensibility and specificity of NeuroQ score threshold to define neurophobia according to the 3 examiners, we obtained a cut-off score of 18 for 2 examiners and a cut-off of 16 for the third one. We therefore chose that a NeuroQ 
score above 16 is a cut-off score defining a neurophobic student, and a neuroQ score above 18 is a cut-off score defining marked neurophobia.

\subsubsection{The Move effect on neurophobia}

During the academic year 2020, 395 medical students participated in the study assessing the effect of The Move teaching on neurophobia. The demographics of the students are presented in Table 2. Mean age was 20.0 years (SD: 2.1 years), and 288 (72.9\%) students were female. Notably, $358(91.1 \%)$ students were previously told that neurology was a complicated subject, but 244 (62.4\%) stated that they were interested in a career in neurology.

Table 3 presents the results of NeuroQ score in total and by item, at baseline and after The Move teaching. At baseline, the mean NeuroQ score was 14.1 (SD: 2.4). By applying the cut-offs determined above, 99 students (25.1\%) were considered neurophobic, and 29 (7.3\%) had marked neurophobia.

Females had higher NeuroQ scores compared to male (mean [SD] neuroQ, 14.3 [2.4] versus 13.5 [2.2], $p=0.002$ ). Item 2 and item 4 scores assessing confidence were the most different between females and males ( $p<0.001$ and $p=0.002$ respectively). Students being told that neurology was a complicated subject had higher NeuroQ scores (mean [SD] NeuroQ, 14.2 [2.4] versus 13.2 [2.1], $p=0.03$ ), while students interested in a career in neurology had lower NeuroQ scores (mean [SD] NeuroQ, 13.7 [2.3] versus 14.7 [2.4], $\mathrm{p}<0.001)$. 
Other demographic characteristics were not significantly associated with baseline NeuroQ score.

After The Move teaching, mean NeuroQ score was 12.9 (SD: 2.8) and was significantly lower compared to baseline NeuroQ score (mean [SD] variation, $-1.1[2.6], p<0.001$ ) (Table 3 and Figure 2A). The number of students with neurophobia at follow-up was 77 (19.5\%), with a trend toward statistically significant difference compared to baseline $(\mathrm{p}=0.07)$ (Figure 2B). This corresponds to an absolute risk reduction of $5.6 \%$ and a relative risk reduction of $22.2 \%$. The number of students with marked neurophobia at follow-up was $20(5.1 \%)$. This corresponds to an absolute risk reduction of $2.3 \%$ and a relative risk reduction of $31.0 \%(\mathrm{p}=0.24)$.

The items that were significantly improved after The Move teaching were items 1, 3 and 5 , the largest difference (-0.5) being for item 5 ("I find it difficult to apply theoretical knowledge in neurology to the clinical examination of the patient") (Table 3).

The difference in NeuroQ score was negatively correlated with the initial NeuroQ score, meaning that improvement in NeuroQ score was greater in students with a higher initial NeuroQ score $(r=-0.39, p<0.001)$. The difference in NeuroQ score was not associated with any of the baseline demographic characteristics.

\subsection{DISCUSSION}


We developed and validated a brief neurophobia screening scale (NeuroQ) suitable for medical students in pre-clinical years. Second, we applied NeuroQ before and after a teaching intervention called "The Move" and found that it reduces neurophobia in preclinical medical students. This scale quantifies baseline neurophobia and can be used to assess the effect of pre-clinical educational interventions in neurology. In addition, our findings highlight the potential utility of pre-clinical educational interventions, such as The Move, in tackling neurophobia.

Our validation process had limitations. No gold standard neurophobia scale exists for pre-clinical medical students. Therefore, we selected a scale already in use in the literature for convergent analysis (Schon questionnaire). This scale was published in English. We directly translated this scale into French rather than applying a rigorous adaptation process. The observed correlation between both this scale and NeuroQ was moderate. The Schon questionnaire does not cover all dimensions of the current neurophobia definition. In addition, the Schon questionnaire and existing neurophobia questionnaires rely on prior exposure to neurology patients, making them less suitable for medical students in pre-clinical years ${ }^{1-3}$. In our study, 27 students $(7 \%$ overall study population), failed to complete a clinically related question in the Schon questionnaire, resulting in missing data. The remaining $93 \%$ of responses may be hypothetical or relate to clinical exposure outside of the neurology curriculum. As there is no existing gold standard questionnaire in the literature covering all aspects of neurophobia we decided to perform convergent validation rather than external validation. For this reason, the Pearson correlation coefficient was expected to be relatively low. This justifies the need for a new scale. 
NeuroQ fills an important gap in the medical education literature. This scale can be used for medical students after completing the neuroscience teaching block and prior to starting neurology clinical clerkships. NeuroQ incorporates the principal components of the neurophobia definition: perceived difficulty and student lack of confidence in neurology ${ }^{10}$. No questions pertained to actual patient encounters, making it suitable for medical students in pre-clinical years. Incorporating these themes only, our scale demonstrated uni-dimensionality. In other words, NeuroQ measures a single construct, neurophobia. Each scale item is derived from the neurophobia definition and therefore captures different aspects of the underlying construct ${ }^{27}$. Including unrelated items, not part of definition, makes test score less representative of the underlying construct ${ }^{27}$. In our study, the preliminary version of the scale included a question on the theoretical idea of examining a patient. This question, deviated from the neurophobia definition, correlated poorly with other scale items and reduced the internal consistency. This question was therefore omitted. Screening is an important part of prevention ${ }^{28}$. Ideally, screening tools should be easy to complete, to ensure adequate response rates and accurate incidence rates of the construct being measured.

Neurophobia is acquired during pre-clinical years ${ }^{8-10}$. Late detection of phobias can lead to avoidance behavior and unsuccessful corrective strategies ${ }^{29}$. We know that neurophobia worsens over the course of medical school ${ }^{18}$ and persists in clinical practice $^{3,12}$. This can lead to diagnostic inaccuracies ${ }^{30}$, an increase in neurology 
referrals and poor patient outcomes ${ }^{31}$. Therefore, strategies are needed to tackle this problem at onset. We identified that neurophobia affected $25 \%$ of our study population at baseline with a female preponderance. This is comparable to incidence rates in the existing literature ${ }^{3,5,8-12}$. While neurology has been highlighted as a difficult subject matter ${ }^{1,5,10}$, interest level amongst medical students and GPs is comparable to other medical specialties ${ }^{31}$. In our study, $62 \%$ of medical students report having an interest in neurology. This is despite $92 \%$ being informed that neurology was a complicated subject. This likely reflects growing societal neurophilia ${ }^{32}$. A previous study highlighted more than half of graduating medical students out-ruled neurology as a future career choice, compared with $20 \%$ during pre-clinical years ${ }^{18}$. This incremental decline in interest suggests neurophobia is an acquired trait and may relate to how we teach neurology. Several studies support this hypothesis and highlight poor teaching as a driver of neurophobia ${ }^{3,5,13}$. Innovative teaching methods can capitalize on the preexisting interest for neurology, as exemplified by our finding that The Move reduces neurophobia.

One of the principal drivers of neurophobia is difficulty integrating neuroscience concepts with clinical signs. The scale item demonstrating the most improvement postteaching intervention was difficulty applying theoretical knowledge of neurology to the clinical scenario. The Move teaching program adopts an immersive and intuitive approach to understanding how neurological disease manifests ${ }^{25,26}$. Through role-play, students assume the patient role, the clinical signs, and thus acquire greater empathy and understanding for how neurological disease manifests clinically. Intuitive teaching approaches can help teach theoretically difficult subjects such as neuroanatomy ${ }^{33,34}$. 
Other examples include the martial art aikido which has been incorporated in highschool physics teaching ${ }^{35}$. Watching masters perform aikido techniques helps students understand difficult physics concepts like the moment of inertia. A teaching movement in the US called STEAM (Science, technology, engineering, arts and mathematics) incorporates arts to facilitate deeper learning in STEAM subjects ${ }^{36}$. Despite a growing literature supporting innovative teaching approaches, traditional lecture-based models seem to predominate in most medical schools worldwide. Incorporating innovative approaches to teaching fundamental neurosciences with The Move teaching may have a synergistic effect on neurophobia.

The learning environment also plays an important role in how we learn and how we consider the discipline we are learning. Optimal learning occurs when the learner perceives mental and emotional well-being ${ }^{37}$. When students feel psychologically safe they imprint newly acquired information into working memory more effectively ${ }^{38}$. The Move has been shown to improve long-term retention and delayed recall of neurology ${ }^{26}$ but has also been assessed by medical students as an emotionally pleasant learning environment ${ }^{25}$. This may in part explain the observed effect this teaching has on neurophobia.

After The Move teaching, the mean NeuroQ score was significantly lower and there was a $22.3 \%$ relative reduction in the number of neurophobic students. First exposure to any neurological teaching might also have similarly improved neurophobia. In the absence 
of control group we cannot evaluate the difference between teaching approaches. It is noteworthy that The Move can be implemented and adapted as a pre-clinical teaching program in different Universities and cultural settings. NeuroQ will allow future studies to evaluate and compare various preclinical educational interventions in neurology. It would also be interesting to understand the impact cultural influences may have played on the neurophobia incidence rates. Similar studies could be replicated using NeuroQ in cohorts of students from other countries. Further study would be also needed to examine the long-term effect of this pre-clinical educational strategy on neurophobia, clinical behavior, and patient care through a long-term longitudinal follow-up of the students. 


\section{Appendix 1}

Eavan McGovern, MD, $\mathrm{PhD}^{*}$, designed the study, had a major role in the acquisition of the data, analyzed data, draft the manuscript

Céline Louapre, $\mathrm{MD}, \mathrm{PhD}^{*}$, had a major role in the acquisition of data, analyzed data, draft the manuscript, performed biostatistical analysis

Julien Cassereau, MD, $\mathrm{PhD}^{*}$, analyzed data, draft the manuscript

Constance Flamand-Roze, $\mathrm{PhD}$, designed the study, had a major role in the acquisition of data, revised the manuscript

Elise Corsetti, PhD, had a major role in the acquisition of data, revised the manuscript

Prasanthi Jegatheesan, PhD, had a major role in the acquisition of data, revised the manuscript

David Bendetowicz, MD, had a major role in the acquisition of data, revised the manuscript

Camille Giron, MD, had a major role in the acquisition of data, revised the manuscript

Margaux Dunoyer, MSc, had a major role in the acquisition of data, revised the manuscript

Nicolas Villain, MD, PhD, had a major role in the acquisition of data, revised the manuscript

Yulia Worbe, MD, PhD, had a major role in the acquisition of data, revised the manuscript

Marie-Christine Renaud, MD, had a major role in the acquisition of data, revised the manuscript

Paul Sauleau, MD, PhD, designed the study, had a major role in the acquisition of data, revised the manuscript

Laure Michel, MD, PhD, designed the study, had a major role in the acquisition of data, revised the manuscript

Marc Vérin, MD, PhD, designed the study, had a major role in the acquisition of data, revised the manuscript 
Bruno Falissard, MD, PhD, designed the study, performed the biostatistical analysis, revised the manuscript

Emmanuel Roze, MD, PhD. designed the study, had a major role in the acquisition of data, analyzed data, draft the manuscript

Data availability statement: The data that support the findings of this study are available from the corresponding author upon reasonable request

\section{Acknowledgement:}

We thank the students and teachers of the Sorbonne University Paris for their implication in this study. We thank Philippine Flamand-Rouvière and Clémence Monnet for their help in preparing the video. 


\section{REFERENCES}

1. Schon F, Hart P, Fernandez C. Is clinical neurology really so difficult? J Neurol Neurosurg Psychiatry. 2002;72(5):557-559. doi:10.1136/jnnp.72.5.557

2. Flanagan E, Walsh C, Tubridy N. Neurophobia attitudes of medical students and doctors in Ireland to neurological teaching. Eur J Neurol. 2007;14(10):1109-1112. doi:10.1111/j.1468-1331.2007.01911.x

3. Fantaneanu TA, Moreau K, Eady K, et al. Neurophobia inception: A study of trainees' perceptions of neurology education. Can J Neurol Sci. 2014;41(4):421429. doi:10.1017/S0317167100018436

4. Matthias AT, Nagasingha P, Ranasinghe P, Gunatilake SB. Neurophobia among medical students and non-specialist doctors in Sri Lanka. BMC Med Educ. 2013;13(1). doi:10.1186/1472-6920-13-164

5. Zinchuk A V., Flanagan EP, Tubridy NJ, Miller WA, Mccullough LD. Attitudes of US medical trainees towards neurology education: "Neurophobia" - A global issue. BMC Med Educ. 2010;10(1). doi:10.1186/1472-6920-10-49

6. Pakpoor J, Handel AE, Disanto G, Davenport RJ, Giovannoni G, Ramagopalan S V. National survey of UK medical students on the perception of neurology. BMC Med Educ. 2014;14(1). doi:10.1186/1472-6920-14-225

7. Jozefowicz R. "neurophobia." Neurophobia. Arch Neurol Neurol. 1994;51(April):328-329.

8. Matthias AT, Nagasingha P, Ranasinghe P, Gunatilake SB. Neurophobia among medical students and non-specialist doctors in Sri Lanka. BMC Med Educ. 2013;13(1). doi:10.1186/1472-6920-13-164

9. Youssef FF. Neurophobia and its implications: Evidence from a Caribbean medical school. BMC Med Educ. 2009;9(1). doi:10.1186/1472-6920-9-39

10. Kam K qian, Tan GSE, Tan K, Lim ECH, Koh NY u., Tan NCK. Neurophobia in medical students and junior doctors--blame the GIK. Ann Acad Med Singapore. 2013;42(11):559-566.

11. BP S, TV C, BR N. Preventing "Neurophobia": Remodeling Neurology Education for 21 st-Century Medical Students through Effective Pedagogical Strategies for 
"Neurophilia." Ann Indian Acad Neurol. 2018;21(1).

doi:10.4103/AIAN.AIAN_371_17

12. McCarron MO, Stevenson M, Loftus AM, McKeown P. Neurophobia among general practice trainees: The evidence, perceived causes and solutions. Clin Neurol Neurosurg. 2014;122:124-128. doi:10.1016/j.clineuro.2014.03.021

13. Abulaban AA, Obeid TH, Algahtani HA, et al. Neurophobia among medical students. Neurosciences. 2015;20(1):37-40. doi:10.17712/nsj.2015.4.20150500

14. McGee J, Maghzi AH, Minagar A. Neurophobia: A global and under-recognized phenomenon. Clin Neurol Neurosurg. 2014;122:iii-iv.

doi:10.1016/j.clineuro.2014.03.023

15. Hudson JN. Linking neuroscience theory to practice to help overcome student fear of neurology. Med Teach. 2006;28(7):651-653. doi:10.1080/01421590600726409

16. Kamour AH, Han DY, Mannino DM, Hessler AB, Kedar S. Factors that impact medical student and house-staff career interest in brain related specialties. $J$ Neurol Sci. 2016;369:312-317. doi:10.1016/j.jns.2016.08.046

17. Shiels L, Majmundar P, Zywot A, Sobotka J, Lau CSM, Jalonen TO. Medical student attitudes and educational interventions to prevent neurophobia: $A$ longitudinal study. BMC Med Educ. 2017;17(1):1-7. doi:10.1186/s12909-0171055-4

18. Conway S, Tubridy N. Neurophobia: More nurture than nature? Ir Med J. 2018;111(3):710. Accessed July 6, 2020. https://pubmed.ncbi.nlm.nih.gov/30376228/

19. Abushouk Al, Duc NM. Curing neurophobia in medical schools: Evidence-based strategies. Med Educ Online. 2016;21(1):1-7. doi:10.3402/meo.v21.32476

20. Sandrone S, Berthaud J V., Chuquilin M, et al. Neurologic and neuroscience education: Mitigating neurophobia to mentor health care providers. Neurology. 2019;92(4):174-179. doi:10.1212/WNL.0000000000006716

21. Chhetri SK. E-learning in neurology education: Principles, opportunities and challenges in combating neurophobia. J Clin Neurosci. 2017;44:80-83. 
doi:10.1016/j.jocn.2017.06.049

22. Ruisoto P, Juanes JA. Fostering Student's Engagement and Active Learning in Neuroscience Education. J Med Syst. 2019;43(3). doi:10.1007/s10916-019-1192$\mathrm{X}$

23. Burford C, Pasha T, lyer P, Rupawala H, Andreica EC, Huett M. Initiatives to reduce neurophobia in medical students: a novel neuroscience conference model. J Neurol Sci. 2019;398:119-120. doi:10.1016/j.jns.2019.01.042

24. Anwar K, Shaikh AA, Sajid MR, Cahusac P, Alarifi NA, AI Shedoukhy A. Tackling student neurophobia in neurosciences block with team-based learning. Med Educ Online. 2015;20(1):1-6. doi:10.3402/meo.v20.28461

25. Roze E, Flamand-Roze C, Meneret A, et al. "The Move", an innovative simulationbased medical education program using roleplay to teach neurological semiology: Students' and teachers' perceptions. Rev Neurol (Paris). 2016;172(4-5):289-294. doi:10.1016/j.neurol.2016.02.007

26. Roze $\mathrm{E}$, Worbe $\mathrm{Y}$, Louapre $\mathrm{C}$, et al. Miming neurological syndromes improves medical student's long-term retention and delayed recall of neurology. J Neurol Sci. 2018;391:143-148. doi:10.1016/j.jns.2018.06.003

27. Ziegler M, Hagemann D. Testing the unidimensionality of items: Pitfalls and loopholes. Eur J Psychol Assess. 2015;31(4):231-237. doi:10.1027/10155759/a000309

28. Iragorri N, Spackman E. Assessing the value of screening tools: Reviewing the challenges and opportunities of cost-effectiveness analysis. Public Health Rev. 2018;39(1):1-27. doi:10.1186/s40985-018-0093-8

29. Cowart MJW, Ollendick TH. Specific Phobias. Wiley-Blackwell Handb Treat Child Adolesc Anxiety. 2012;5(8):353-368. doi:10.1002/9781118315088.ch16

30. O'Sullivan SS, Redwood RI, Hunt D, McMahon EM, O'Sullivan S. Recognition of psychogenic non-epileptic seizures: A curable neurophobia? J Neurol Neurosurg Psychiatry. 2013;84(2):228-231. doi:10.1136/jnnp-2012-303062

31. Loftus AM, Wade C, McCarron MO. Primary care perceptions of neurology and neurology services. Postgrad Med J. 2016;92(1088):318-321. 
doi:10.1136/postgradmedj-2015-133683

32. Fuller GN. Neurophilia: A fascination for neurology-a new syndrome. Pract Neurol. 2012;12(5):276-278. doi:10.1136/practneurol-2012-000400

33. Dao V, Yeh PH, Vogel KS, Moore CM. Applied neuroanatomy elective to reinforce and promote engagement with neurosensory pathways using interactive and artistic activities. Anat Sci Educ. 2015;8(2):166-174. doi:10.1002/ase.1469

34. Dickson KA, Stephens BW. It's all in the mime: Actions speak louder than words when teaching the cranial nerves. Anat Sci Educ. 2015;8(6):584-592. doi:10.1002/ase.1531

35. Corbi A, Santos OC, Burgos D. Intelligent framework for learning physics with aikido (martial art) and registered sensors. Sensors (Switzerland). 2019;19(17):118. doi:10.3390/s19173681

36. Land MH. Full STEAM ahead: The benefits of integrating the arts into STEM. Procedia Comput Sci. 2013;20:547-552. doi:10.1016/j.procs.2013.09.317

37. Caverzagie KJ, Goldenberg MG, Hall JM. Psychology and learning: The role of the clinical learning environment. Med Teach. 2019;41(4):375-379. doi:10.1080/0142159X.2019.1567910

38. Young JE, Williamson MI, Egan TG. Students' reflections on the relationships between safe learning environments, learning challenge and positive experiences of learning in a simulated GP clinic. Adv Heal Sci Educ. 2016;21(1):63-77. doi:10.1007/s10459-015-9611-3 
Figure 1: Design of the study
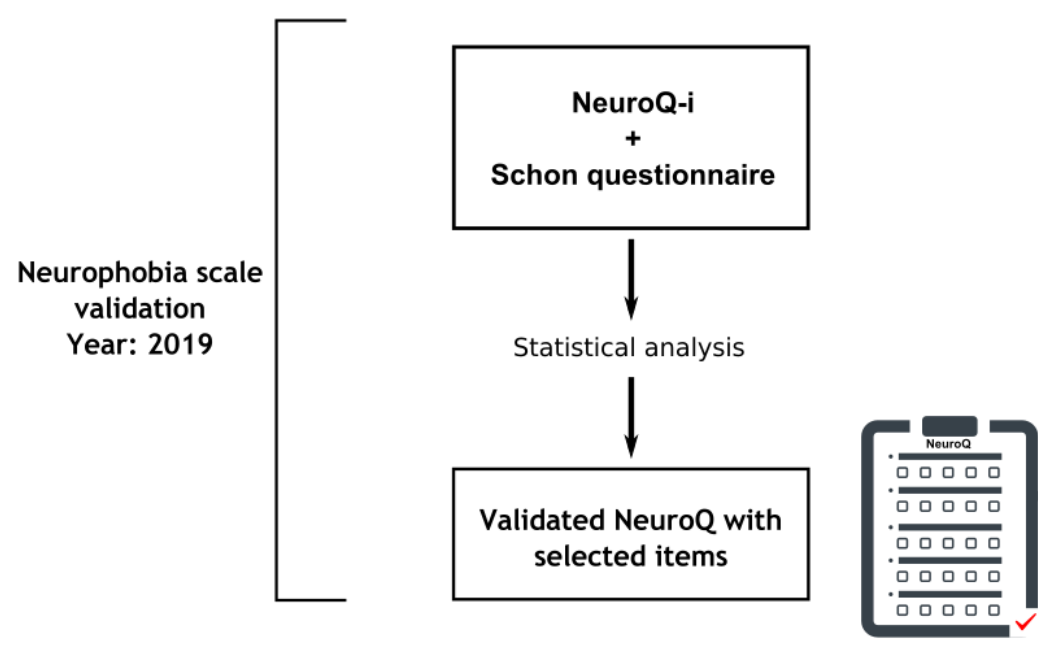

The Move effect on neurophobia

Year: 2020

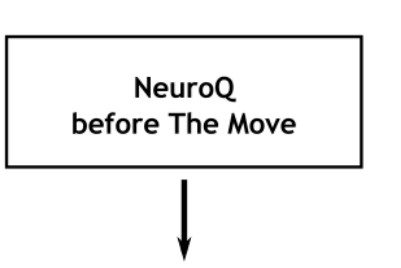

\begin{tabular}{|c|}
\hline व ४०० \\
\hline ৫৫४ ৫ \\
\hline ०००ष० \\
\hline 00008 \\
\hline 0008 \\
\hline
\end{tabular}

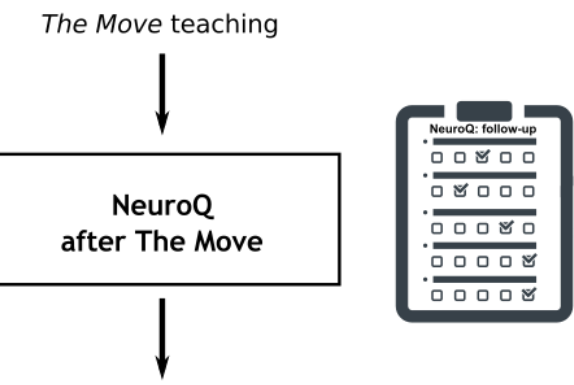

Statistical analysis 
Table 1: NeuroQ - validated neurophobia scale

\begin{tabular}{|c|c|c|c|}
\hline \multicolumn{2}{|c|}{ Original french version } & \multicolumn{2}{|c|}{ Translated English version (publication purposes) } \\
\hline Propositions & Cochez votre réponse & Statement & Select your answer \\
\hline $\begin{array}{l}\text { 1. Je trouve que les } \\
\text { concepts en neurologie } \\
\text { sont difficiles à } \\
\text { comprendre }\end{array}$ & $\begin{array}{l}1=\text { fortement en désaccord } \\
2=\text { pas d'accord } \\
3=\text { ni d'accord ni en } \\
\quad \text { désaccord } \\
4=\text { d'accord } \\
5=\text { tout à fait d'accord }\end{array}$ & $\begin{array}{l}\text { 1. I find neurological } \\
\text { concepts difficult to } \\
\text { understand }\end{array}$ & $\begin{array}{l}1=\text { strongly disagree } \\
2=\text { disagree } \\
3=\text { neither agree nor } \\
\quad \text { disagree } \\
4=\text { agree } \\
5=\text { totally agree }\end{array}$ \\
\hline $\begin{array}{l}\text { 2. J'ai confiance en ma } \\
\text { capacité à comprendre } \\
\text { la neurologie }\end{array}$ & $\begin{aligned} 5 & =\text { fortement en désaccord } \\
4 & =\text { pas d'accord } \\
3 & =\text { ni d'accord ni en } \\
& \text { désaccord } \\
2 & =\text { d'accord } \\
1= & \text { tout à fait d'accord }\end{aligned}$ & $\begin{array}{l}\text { 2. I have confidence in my } \\
\text { ability to understand } \\
\text { neurological concepts }\end{array}$ & $\begin{aligned} 5 & =\text { strongly disagree } \\
4 & =\text { disagree } \\
3 & =\text { neither agree nor } \\
& \text { disagree } \\
2 & =\text { agree } \\
1 & =\text { totally agree }\end{aligned}$ \\
\hline $\begin{array}{l}\text { 3. En comparaison aux } \\
\text { autres spécialités de } \\
\text { médecine, je trouve } \\
\text { que la neurologie est } \\
\text { plus compliquée }\end{array}$ & $\begin{aligned} 1 & =\text { fortement en désaccord } \\
2 & =\text { pas d'accord } \\
3= & \text { ni d'accord ni en } \\
& \text { désaccord } \\
4 & =\text { d'accord } \\
5 & =\text { tout à fait d'accord }\end{aligned}$ & $\begin{array}{l}\text { 3. Compared to other } \\
\text { medical specialties I find } \\
\text { neurology is more } \\
\text { complicated }\end{array}$ & $\begin{array}{l}1=\text { strongly disagree } \\
2=\text { disagree } \\
3=\text { neither agree nor } \\
\quad \text { disagree } \\
4=\text { agree } \\
5=\text { totally agree }\end{array}$ \\
\hline $\begin{array}{l}\text { 4. J'ai confiance en ma } \\
\text { capacité à étudier la } \\
\text { neurologie }\end{array}$ & $\begin{aligned} 5 & =\text { fortement en désaccord } \\
4 & =\text { pas d'accord } \\
3 & =\text { ni d'accord ni en } \\
& \text { désaccord } \\
2= & \text { d'accord } \\
1= & \text { tout à fait d'accord }\end{aligned}$ & $\begin{array}{l}\text { 4. I have confidence in my } \\
\text { ability to study neurology }\end{array}$ & $\begin{array}{l}5=\text { strongly disagree } \\
4=\text { disagree } \\
3=\text { neither agree nor } \\
\text { disagree } \\
2=\text { agree } \\
1=\text { totally agree }\end{array}$ \\
\hline $\begin{array}{l}\text { 5. Je trouve qu'il est } \\
\text { difficile d'appliquer les } \\
\text { connaissances } \\
\text { théoriques en } \\
\text { neurologie à l'examen } \\
\text { clinique du patient }\end{array}$ & $\begin{aligned} 1 & =\text { fortement en désaccord } \\
2 & =\text { pas d'accord } \\
3= & \text { ni d'accord ni en } \\
& \text { désaccord } \\
4 & =\text { d'accord } \\
5 & =\text { tout à fait d'accord }\end{aligned}$ & $\begin{array}{l}\text { 5. I find it difficult to apply } \\
\text { theoretical knowledge in } \\
\text { neurology to the clinical } \\
\text { examination }\end{array}$ & $\begin{array}{l}1=\text { strongly disagree } \\
2=\text { disagree } \\
3=\text { neither agree nor } \\
\quad \text { disagree } \\
\begin{aligned} 4= & \text { agree } \\
& 5 \quad=\text { totally agree }\end{aligned}\end{array}$ \\
\hline
\end{tabular}


*Note that scoring did not appear in the student's questionnaire. It is present in the table for the purposes of ease of scoring

Table 2: Demographics of students participating in the study assessing The Move effect on neurophobia

\begin{tabular}{|l|c|c|c|}
\hline & All & Female & Male \\
\hline Number of Students & 395 & 288 & 107 \\
\hline Age, mean (SD) & $20.0(2.1)$ & $19.9(2.2)$ & $20.1(2.0)$ \\
\hline $\begin{array}{l}\text { Presence of doctor } \\
\text { among family members, } \\
\mathrm{n} \text { (\%) }\end{array}$ & $159(40.2 \%)$ & $116(40.3 \%)$ & $43(40.2 \%)$ \\
\hline $\begin{array}{l}\text { Family or close circles } \\
\text { working in neurology, } \mathrm{n} \\
\text { (\%) }\end{array}$ & $16(4.1 \%)$ & $13(4.5 \%)$ & $3(2.8 \%)$ \\
\hline $\begin{array}{l}\text { Family or close friends } \\
\text { affected by a } \\
\text { neurological disease, } \mathrm{n} \\
\text { (\%) }\end{array}$ & $167(42.4 \%)$ & $122(42.5 \%)$ & $45(42.1 \%)$ \\
\hline $\begin{array}{l}\text { Previously told that } \\
\text { neurology was a } \\
\text { complicated subject, } \mathrm{n} \\
\text { (\%) }\end{array}$ & $358(91.1 \%)$ & $264(92.3 \%)$ & $98(64.1 \%)$ \\
\hline $\begin{array}{l}\text { Interested in a career in } \\
\text { neurology, } \mathrm{n}(\%)\end{array}$ & $244(62.4 \%)$ & $176(61.7 \%)$ & \\
\hline
\end{tabular}


Table 3: NeuroQ at baseline and follow-up.

\begin{tabular}{|l|c|c|c|}
\hline & Baseline & Follow-up & p-value \\
\hline Total NeuroQ & $14.1(2.4)$ & $12.9(2.8)$ & $<0.001$ \\
\hline $\begin{array}{l}\text { Q1: I find neurological } \\
\text { concepts difficult to } \\
\text { understand }\end{array}$ & $3.4(0.8)$ & $3.1(0.9)$ & $<0.001$ \\
\hline $\begin{array}{l}\text { Q2: I have confidence } \\
\text { in my ability to } \\
\text { understand } \\
\text { neurological concepts }\end{array}$ & $2.2(0.7)$ & $2.1(0.7)$ & ns \\
\hline $\begin{array}{l}\text { Q3: Compared to } \\
\text { other medical } \\
\text { specialties, I find that } \\
\text { neurology is more } \\
\text { complicated }\end{array}$ & $3.4(0.8)$ & $3.1(0.9)$ & $<0.001$ \\
\hline $\begin{array}{l}\text { Q4: I have confidence } \\
\text { in my ability to study } \\
\text { neurology }\end{array}$ & $2.0(0.7)$ & $2.0(0.7)$ & ns \\
\hline $\begin{array}{l}\text { Q5: I find it difficult to } \\
\text { apply theoretical } \\
\text { knowledge to the } \\
\text { the patient }\end{array}$ & $3.1(0.9)$ & $2.6(1.0)$ & $<0.001$ \\
\hline
\end{tabular}

Results are expressed as mean (standard deviation). P-values are calculated from paired t-test (for total NeuroQ) or signed ranx Wilcoxon test (for individual items) comparing up and baseline scores. Ns: non-significant. 
Figure 2 NeuroQ scores and proportion of students with neurophobia before and after The Move teaching

A. Difference in neuroQ score, by paired t-test, at baseline (Before) and follow-up (After)

$B$. Difference in the number of students classified with neurophobia (orange) as defined by NeuroQ score $\geq 16$, at baseline (Before) and follow-up (After), by Fisher exact test. ARR: absolute reduction risk; RRR: relative reduction risk

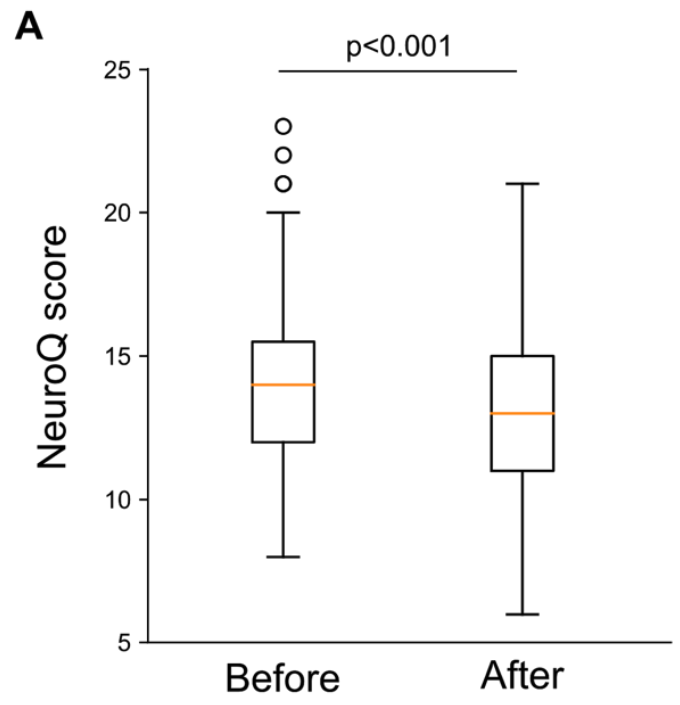

B

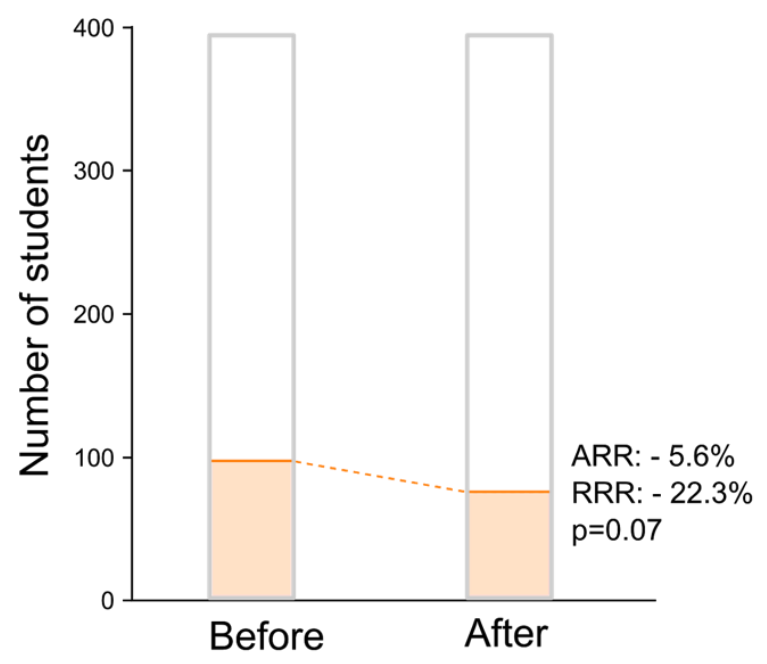




\section{HIGHLIGHTS}

- Neurophobia is a fear of neuroscience and neurology

- Neurophobia starts in pre-clinical years in medical school

- NeuroQ questionnaire is a validated tool to measure neurophobia in medical students and the effect of a teaching intervention

- The Move neurology teaching program improves neurophobia 